\title{
THE RESULTS OF RAISING THE RESECTABILITY RATE IN OPERATIONS FOR LUNG CARCINOMA
}

\author{
BY \\ R. ABBEY SMITH \\ From the Thoracic Surgical Unit, King Edward VII Memorial Hospital, Warwick
}

(RECEIVED FOR PUBLICATION SEPTEMBER 5, 1956)

The results of treating lung carcinoma by removing the growth in each case in which the lesion is explored by thoracotomy in a consecutive series are presented in this paper. This attempt to remove the lung containing the growth, whatever its local extent, originated in three principal considerations: that surgical removal offers at present the only hope of cure, that resection of the growth is the best palliative procedure available (Thompson, 1952 ; Ochsner, Ray, and Acree, 1954), and that the results, in terms of palliation, of exploration only are so poor. Clearly the major issue with which this contribution is concerned is whether it is more beneficial to resect a locally advanced growth even though portions are not eradicated than to close the chest with minimum exploration and treat the patient by some alternative palliative method such as deep $x$-ray therapy. A distinction must be made between the objectives of this palliative operation and the radical pneumonectomy with block dissection of glands recently described by Brock and Whytehead (1955). One is classical cancer surgery ; to accept the other a material change of outlook on the place of surgery in lung cancer would be required. A number of factors prevent a sound conclusion being reached on the wisdom of palliative resection. There would not be, for instance, general agreement that resection is the best palliative, nor are the criteria of what constitutes a good palliative treatment immediately obvious, especially in the patient symptomless at the time of operation, unless each individual case of a series is discussed separately. There are also differences of opinion about the pre-operative signs of an inoperable lesion. It could be maintained that a number of the lesions in this series would be considered inoperable if such examinations as a barium swallow, angiocardiography, and two-plane tomography had been more consistently used as a routine investigation. To withhold operation and deny all chance of cure, therefore, on the evidence of one or other of these ancillary investigations, particularly in the young robust patient, is a decision of some gravity. Only in the circumstances of making patients symptomatically worse by performing palliative pneumonectomy or of a prohibitive operative mortality were we prepared to alter this policy of resecting the lesion on each occasion that a decision to operate had been reached.

There has been no intentional operating on clearly inoperable lesions, and the effect of resecting the lesion as against closing the chest, where extension is more locally advanced than could be anticipated pre-operatively, is the only matter for discussion. Most surgeons would regard operation as necessary in all cases in this series, and this seems a fair but brief summary of the type of lesion under review. It should be mentioned that the patient's symptoms have not been considered in coming to a decision on the operability of a lesion or otherwise.

\section{The Cases Under Review}

During this trial 147 cases of lung carcinoma were operated on consecutively and the growth removed either by pneumonectomy or lobectomy in 143 , a resectability rate of $97.2 \%$. All the patients were followed up frequently and as much information as possible was obtained about the nature of the terminal illness by personal observation. The outcome is known, in detail, of every case operated on. At the time of operation notes were made as to whether the operation was curative or palliative. In this context a palliative operation was regarded as one in which obvious and unmistakable tumour tissue in either the great vessels, lymph glands, the bronchi, or the chest wall was incompletely removed because of its inaccessibility. Where obviously involved glands or tumour in the atrium appeared to be completely resected with the main mass of growth, the operation was considered, for comparative purposes, to give a chance of cure and to be therefore curative in nature. Classifying into the two groups as defined, 95 were curative and 48 palliative operations. Such a 
small number of cases seems worth while analysing and reporting at this stage not necessarily to commend the procedure but to enable a comparison to be made with available methods of palliation from the time of operation on a locally advanced inoperable growth to the death of the patient. If a resectability rate of $70 \%$ is regarded as standard, there remain 30 out of every 100 patients explored for whom a palliative must be available. This $70 \%$ resectability rate has additional significance. It is a measure of the compelling reasons that exist to offer a chance of cure by operation and of the impossibility of finally determining resectability except by thoracotomy. Some of the 48 cases in this series, where a palliative resection was done, possibly form a comparable group to the inoperable group of cases in other series. In comparing the results of resection in this series with the fate of the inoperable cases in others, similar lesions are in some respects being compared. This contentious statement does not presume that anyone except the operating surgeon can decide which lesion is correctly treatable by a resection which does not remove the entire growth. It is rather a natural sequel to a different, and perhaps unwise, approach to a distressingly familiar problem.

\section{The Operation}

At operation the patient was placed in the facedown (Overholt) position, and in the general conduct of the operation the accounts of pneumonectomy in the face-down position by Sellors (1950, 1952) have been closely followed. Only the features peculiar to a palliative procedure need be described. The most significant of these is that the actual growth must be transected in completing the resection, and it is with the results of this, the palliative operation, that this paper is concerned. Two principles were followed in isolating and securing the structures from within the malignant mass at the hilum. One, that control of the hilum might be obtained by dividing the pericardium along its whole circumference, when possible before the hilar dissection is started; the other that the least involved part of the hilum is dissected first. Although initially it seemed probable that the vessels would present the greatest difficulty, it is in fact on the state of the main bronchus, especially on the left side, on which resectability finally depends, and for this reason the pre-operative bronchoscopy to assess the involvement of the carina, main stem bronchus and the lower trachea is the most informative means of determining resectability. While the pulmonary vessels in these growths of surgical dimensions can be secured in some fashion or other, the bronchus, if involved beyond the limits where normal bronchus or trachea can be reached, may have to be sutured with growth in situ, thus increasing the liability to fistula formation. In this event the palliative value of the operation is immediately jeopardized. Repeated improvisation is the essential tactic for dissection of the hilum when the growth is advanced, and some experiences of this process will be described. The bronchus on the right side after division of the azygos vein presents no problem. Any subcarinal glands because of their relatively safe position are forcibly freed, and if division of the main stem bronchus needs to be at the level of the carina the tracheal wall can be sutured. On the left side extension around the bronchus and its fixity to the aortic arch may result in growth, either in glands or in the mucosa itself, being included in the suture line. Of the two broncho-pleural fistulae that ensued, both followed resection of left-sided main stem growths and in . each case the patient died in hospital. By piecemeal removal of growth from under the arch a sufficient amount may be cleared to allow a clear bronchial suture line. In one case the aortic arch was mobilized by division of six pairs of inter- $\stackrel{\mathbb{D}}{\mathbb{2}}$ costals, the divided bronchus delivered above the $\overrightarrow{\vec{F}}$ arch and the tracheal wall sutured after excision of the residual growth on the bronchus. A satisfactory immediate result was obtained.

The right pulmonary artery in its intrapericardial course seems almost immune from direct invasion by growth. In the 73 right-sided opera- $\cong$ tions the artery was secured in every case and in 0 none was it necessary to leave growth in or around the divided stump. In its more peripheral course, $\delta$ however, the right pulmonary artery may be inextricably fixed to the superior vena cava by spread from an upper lobe growth. An essential $>$ preliminary to exposure of the artery, with the patient in the prone position, is division of the main bronchus and strong lateral retraction of the growth and glands lying between the oesophagus $N$ and the posterior pericardium. In this way an area of pericardium is exposed, and, by picking up the membrane overlying the space between the pul-o monary artery and the upper pulmonary vein, the $\stackrel{\mathbb{D}}{\overparen{D}}$ pericardial cavity is entered and the artery secured. $\stackrel{\oplus}{+}$ In five of the right-sided operations the artery was clamped, divided, and sutured within the peri- $\frac{0}{\Phi}$ cardium. This was done not necessarily because $\stackrel{\mathbb{\rho}}{\stackrel{\odot}{\circ}}$ of an insufficient length of artery to ligate, but by $\mathbb{Q}$ so doing a wider margin free from growth is $\overline{2}$ obtained. What appears to be an adequate length $\delta$ 
of artery may, after ligation in continuity, be reduced to indivisible proportions through the contracting effect of the ligature. A half-centimetre length of artery protruding through the jaws of a centrally placed clamp is sufficient to insert a number of interrupted haemostatic sutures into. In contrast to the invulnerability of the intrapericardial right pulmonary artery, the left-sided and the main pulmonary artery may both be involved by growth, commonly at the site of origin of one from the other. Various methods have been used to contain the artery before division. The most helpful of these is to leave this part of the hilar dissection to the last, and by judicious manipulation of the mobilized lung a controllable length of the artery becomes available. In one case a Potts-Smith clamp was applied around the main pulmonary artery before division and suture of the branch to the left lung. In two other cases prolonged pressure on a suture line on the main trunk, which appeared unsound after release of a clamp, was necessary, and in one of these obstruction to the right heart outflow, by holding the main pul-

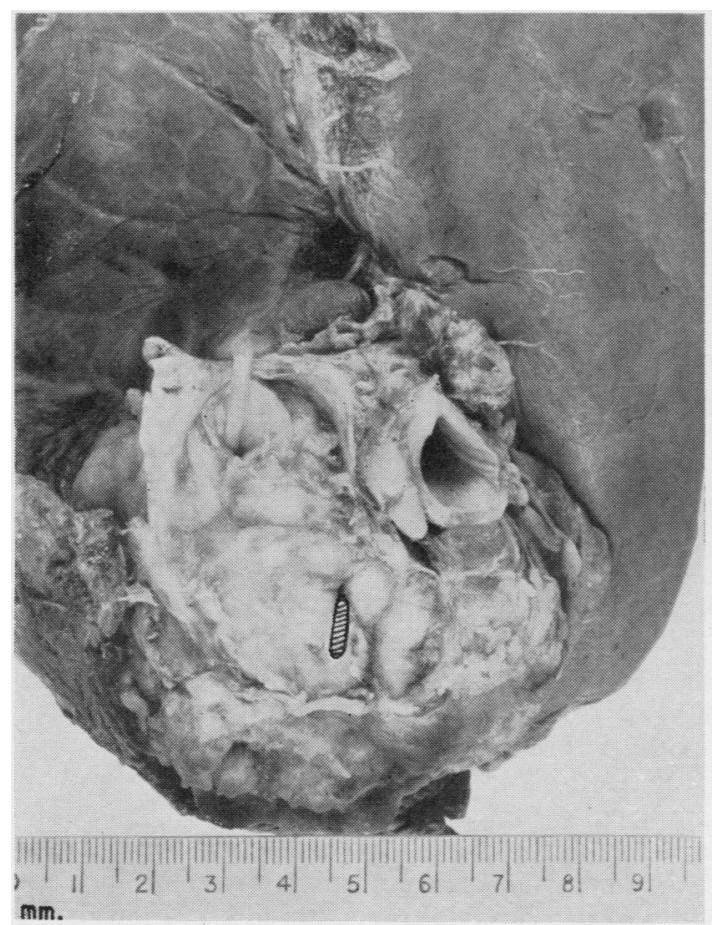

FIG. 1.- Hilum of left lung showing involvement of the intrapericardial course of the left pulmonary artery (shaded probe). Another probe is in the inferior pulmonary vein; the superior pulmonary vein is completely obscured by growth. The cut edge of the pericardium surrounds the mass of growth. Patient alive eight months after palliative pneumonectomy. monary trunk between thumb and finger, was tolerated for periods up to five beats of the heart. This patient (Case L. J., Table II) is bricklaying 26 months after resection. In six of the left-sided resections it was not possible to remove the lung except by transecting the growth and leaving fragments of varying size on the main pulmonary trunk or the sutured left pulmonary branch. Fig. 1 illustrates gross involvement of the left pulmonary artery. In this particular case a Brock mitral clamp was placed longitudinally on the main pulmonary artery, causing as little obliteration of the flow as possible. The left pulmonary artery with the encircling growth was cut through with a scalpel. No clamp need be placed (and in some cases cannot be) on the distal end of the artery before division even when the veins are not controlled, and no serious bleeding has occurred provided that traction on the open distal end is maintained. Growth in the stump to be sutured does not prevent a satisfactory closure, if the sutures are not too tightly tied and a sufficient number used before the clamp is released. Reapplication of a clamp to a bleeding suture line flush with the main trunk is difficult and the need for it best avoided by inserting a large number of sutures. If this is insufficient prolonged pressure has been preferred to the insertion of additional sutures. The soft encephaloid mass, part growth, part arterial stump, is able to hold haemostatic sutures because of the resistance of the arterial wall to invasion by growth. This may be confirmed by microscopical examination of the arterial wall and its malignant collar in such cases. Some elastic fibres always seem to remain.

To summarize, it seems there are grounds for supposing that the pulmonary artery on either side may almost always be controlled provided the feasibility of cutting across growth is confirmed. There have been no hospital deaths attributable to this method (Table I).

The pulmonary veins and atrium may be encroached on in a number of different ways. Alwyn (1951) has amply discussed the subject. Commonly involvement is by spread of growth along the outside of the vein on to the wall of the auricle. In favourable circumstances a clamp may be placed across the atrial wall to include all the growth in the excision. In more advanced lesions the clamp is so placed as to include as much of the growth as possible. If this position of the clamp causes an alteration of cardiac rhythm and fall in blood pressure it is readjusted immediately to cause less constriction of the chamber. In this way one may be forced into 
cutting across growth on the atrium, and sewing through it, to shut the atrium before removing the clamp. One early case had a lung tourniquet carrying picture cord placed around the growth on the atrium, at a stage when no other means of completing the operation seemed available. On cutting through the growth it was seen to be almost fluid, and so deeply had the cord sunk in that its removal from the atrium was impossible. The two limbs of the cord were firmly ligated together and the lung and instrument cut free leaving the cord as the haemostatic around the atrium. The patient (Case W. B., Table II) resumed his former occupation as a fitter for 14 months. His survival encouraged the hope that extension of residual cancer in the heart and great vessels can be relatively slow. In other instances the atrium may contain a mass of tumour, the vein walls themselves being free from invasion. A tumour thrombus of about the size of a golf ball was palpable in the atrium in three cases of this series, each from a right lower lobe carcinoma. In one, the mass was removed with the pneumonectomy specimen by a circular division of the atrium wall

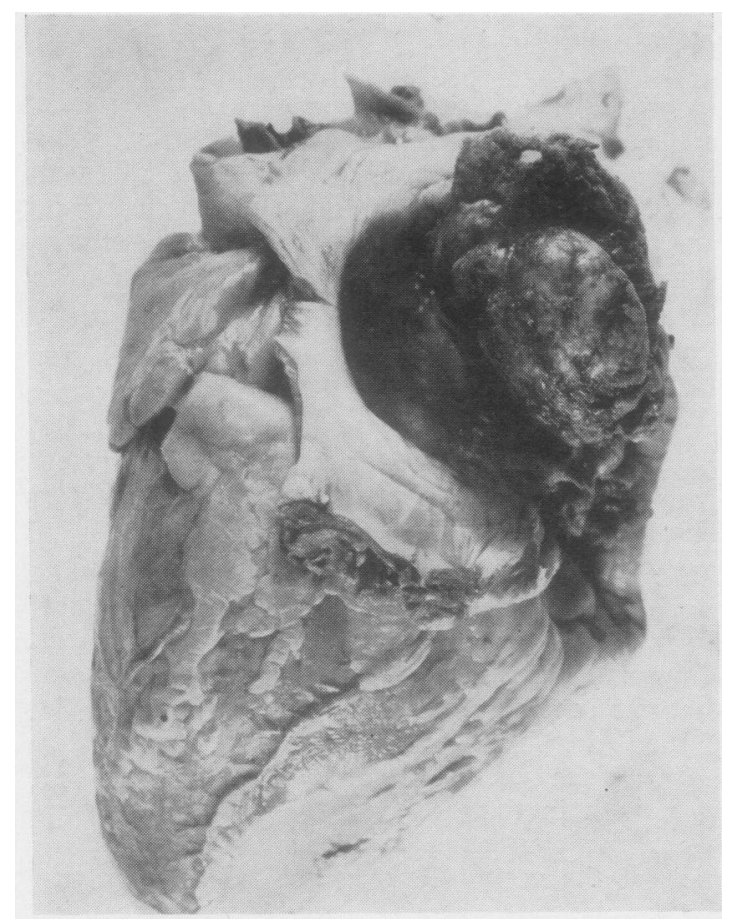

FIG. 2.-Heart with left atrium opened showing growth within the atrium. Spread has taken place along the lumen of the inferior pulmonary vein. Death on second day after palliative pneumonectomy (see text for description). at its junction with the vein. Simultaneous release $\stackrel{\overrightarrow{\vec{D}}}{\stackrel{\vec{\rho}}{+}}$ of a previously placed clamp and traction on the lung expelled the thrombus apparently complete. 흠 The clamp was reapplied and the atrium sutured. $\frac{\bar{\sigma}}{\sigma}$ In the two other cases the wall of the atrium was $\cong$ clamped and the tumour tissue transected, leaving the bulk of the thrombus within the atrium. Fig. 2 is a photograph of the heart of one of these cases. This patient (Case 5, Table I) died from $\vec{\omega}$ cardiac failure associated with paroxysmal tachycardia on the second post-operative day; the $\underset{x}{\vec{x}}$ other two were discharged from hospital after a $\vec{N}$

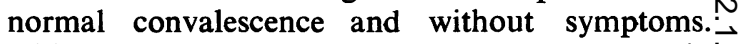
Although advanced degrees of pulmonary vein $\gamma$ and atrial involvement have not precluded resec- 0 tion from which satisfactory palliation is to be expected, the reverse seems true when the superior $\vec{z}$ vena cava is invaded. Although any patient with evidence of caval obstruction was rejected for⿳⺈ operation, three cases were encountered in which $\overrightarrow{ }$ the space between the extrapericardial pulmonaryo artery and the superior vena cava was obliterated. by growth. Our small experience of removing such awkwardly placed tumours confirms the generally held view that such attempts are not worth while,o especially if the finding is an unexpected oneo during the course of a severe operation. It seems, $\stackrel{\mathbb{Q}}{\Omega}$ moreover, that by anticipating such a state of $\overrightarrow{0}$ affairs before operation, little can be gained from 3 any reconstructive operation on the vena cava as? a palliative measure in lung carcinoma. The three patients with caval involvement died directly from operation. One had numerous glands distortingo the azygos vein, the vena cava, and the pulmonary artery. After ligation of the artery inside the peri-o cardium, the glands were dissected off the vena cava in too deep a plane; the vein, displaced byo finger dissection, was stretched over the finger and therefore emptied of blood. It was ligated in con-음 tinuity as part of the gland mass. The first indica- $\rightarrow$ tion of this accident was an abrupt stoppage of the blood drip into the patient's arm. The patient's heart beat continued for 90 minutes, but nothing positive could be done to retrieve the situation 0 In the other two patients the growth had extendedw directly into the superior vena cava at the level op the pericardial reflection. The hilar dissection waso completed within the pericardium, the lung remain ing tethered to the vena cava. There seemed some ${ }^{+}$ chance of total excision and removal of the cer $=0$ tainty of vena caval obstruction later. In attempt $\frac{\text { Oे }}{8}$ ing this the vein was damaged in both cases, and although haemostasis was achieved both patient 8 died during the first 20 hours, probably frone obstruction to the venous return by pressure and 
partial occlusion during the repair. Blood loss hardly seemed sufficient to be the principal cause of death. Of all the vessels which may be entangled by growth, the superior vena cava seems least tolerant of operative intervention on this evidence, and is the exception to the generalization that the state of the great vessels is of secondary importance to that of the main bronchus in assessing the immediate risk of palliative resection.

Three patients had microscopically confirmed involvement of rib requiring removal of portions of the chest wall. One of these patients exhibited the unusual symptom of recurrent episodes of subcutaneous surgical emphysema from a communication between a breaking down neoplasm of the lower lobe and the subcutaneous tissues. He lived in comfort for seven months after operation.

Although superficial fixation of mediastinal glands to the oesophageal wall is usual, the mucosa has not been eroded in any case of the series; these glands have therefore been more readily freed than would have been the practice had experience shown erosion through to the mucosa to be commonplace. Clearance of deeply placed glands was associated with a tear of the contralateral pleura on one occasion without ill effect on the patient's convalescence. In another patient a segment of the oesophagus was found to be involved by direct spread of growth from the right lower lobe. A wedge of oesophagus was resected, the ends reunited, and the pneumonectomy completed. Although this patient returned to work seven weeks after operation he died from an acute respiratory illness five months later.

The four patients with unresectable growths had left-sided tumours, and showed radiographic evidence of hilar gland enlargement, and the bronchoscopic findings indicated fixity of the main bronchus on the side of the growth. In two of these patients the gland mass presented as part of the wall of the aorta along the whole concavity of the arch; in a third the pulmonary artery was sutured at its origin, but the patient's condition deteriorated to such an extent following a difficult dissection of the mediastinum that the operation was not completed. In the fourth case the custom of controlling the hilum by a circular division of the pericardium and leaving the difficult part of the dissection to the last was not observed. A preliminary and exploratory dissection of the glands around the artery caused a major tear in the vessel which could not be made good. The artery itself was not visible and more or less blind methods of controlling the haemorrhage were ineffective. The patient died during operation. The fact that the unresectable growths were left-sided confirms the greater vulnerability of the left pulmonary artery to involvement as compared with the right and illustrates the considerable limitations to full exposure which the aortic arch imposes in cases where the curve of the arch is found at operation to be filled by a homogeneous malignant mass.

\section{RESULTS}

Considering the whole series, 147 cases were operated on, the growth removed in 143 and of these 18 died in hospital after operation. Of the 143 patients, 48 were considered palliative resections and of these 48 patients 10 died in hospital. The operative deaths for this group are summarized in Table I. Excluding the operative deaths,

TABLE I

TEN OPERATIVE DEATHS IN A SERIES OF 48 CASES

\begin{tabular}{|c|c|c|c|c|c|}
\hline $\begin{array}{l}\text { Case } \\
\text { No. }\end{array}$ & Age & Side & $\begin{array}{c}\text { Site of } \\
\text { Residual } \\
\text { Carcinoma }\end{array}$ & $\begin{array}{c}\text { Time } \\
\text { after } \\
\text { Operation }\end{array}$ & Cause of Death \\
\hline 1 & 54 & $\mathbf{R}$ & Mediastinal glands & At opera- & Ligation of S.V.C. \\
\hline 2 & 58 & $\mathbf{R}$ & Around S.V.C. & $\begin{array}{l}\text { tion } \\
\text { lst day }\end{array}$ & Tear of S.V.C. \\
\hline $\begin{array}{l}3 \\
4\end{array}$ & $\begin{array}{l}51 \\
46\end{array}$ & $\begin{array}{l}\mathbf{R} \\
\mathbf{R}\end{array}$ & $\begin{array}{l}\text { Glands and bron- } \\
\text { chus }\end{array}$ & $\begin{array}{l}\text { 1st ,", } \\
\text { 2nd ,", }\end{array}$ & Shock" ," \\
\hline $\begin{array}{l}5 \\
6\end{array}$ & $\begin{array}{l}49 \\
55\end{array}$ & $\begin{array}{l}\mathbf{R} \\
\mathbf{R}\end{array}$ & $\begin{array}{l}\text { In atrium (Fig. 2) } \\
\text { Supra azygos } \\
\text { glands }\end{array}$ & $\begin{array}{l}\text { 2nd ,, } \\
\text { 2nd ,, }\end{array}$ & $\begin{array}{l}\text { Cardiac failure } \\
\text { Coronary throm- } \\
\text { bosis }\end{array}$ \\
\hline 7 & 53 & $\mathbf{L}$ & $\begin{array}{l}\text { Around ascending } \\
\text { aorta }\end{array}$ & & $\begin{array}{l}\text { Probably respira- } \\
\text { tory, no necropsy }\end{array}$ \\
\hline 8 & 57 & $\mathbf{L}$ & $\begin{array}{l}\text { Bronchus and pul- } \\
\text { monary artery }\end{array}$ & 12 th , & $\begin{array}{l}\text { Broncho-pleural } \\
\text { fistula }\end{array}$ \\
\hline 9 & 62 & $\mathbf{L}$ & Bronchial stump & 12 th , , & $\begin{array}{l}\text { Broncho-pleural } \\
\text { fistula }\end{array}$ \\
\hline 10 & 57 & $\mathbf{R}$ & On atrium wall & 18 th, & $\begin{array}{l}\text { Haemorrhage from } \\
\text { duodenal ulcer }\end{array}$ \\
\hline
\end{tabular}

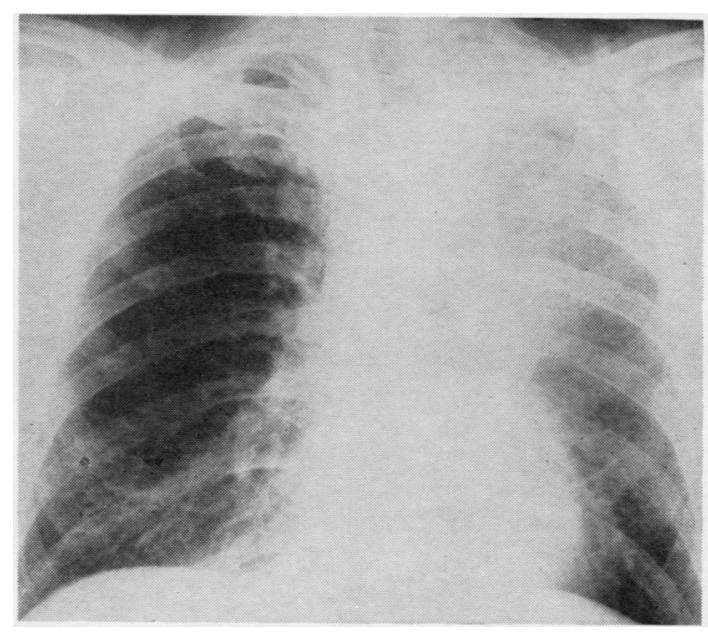

FIG. 3.-Case L. J. (Table II). Pre-operative radiograph. Patient working 26 months after palliative pneumonectomy. Growth remains on pulmonary artery. 


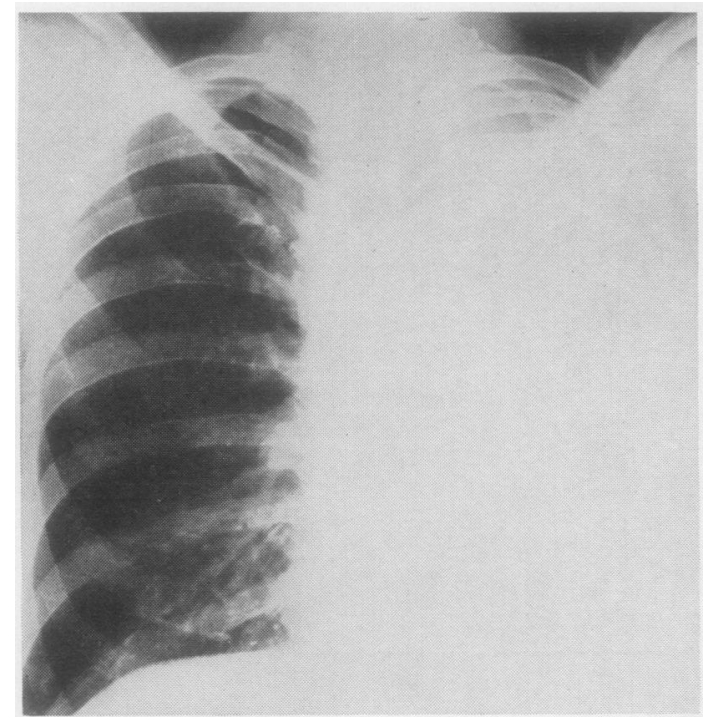

FIG. 4.-Case H. G. (Table II). Pre-operative radiograph. Patient working 24 months after palliative pneumonectomy. Growth remains in inaccessible mediastinal glands.

all but two of the survivors (36) were able to leave hospital for their homes before the sixteenth postoperative day, an important aspect of a palliative procedure. These patients were observed at frequent intervals and the operation was con-

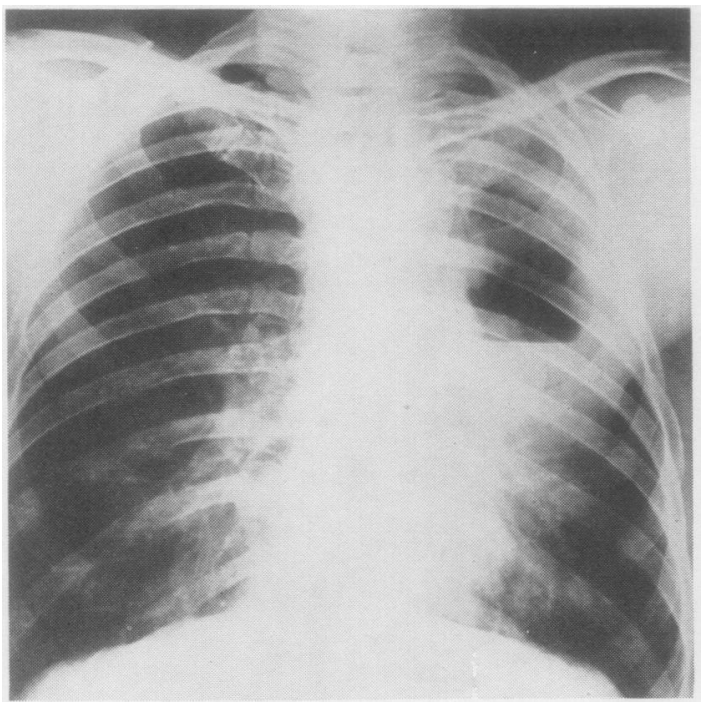

Fig. 6.-Case J. P. (Table II). Pre-operative radiograph. Patient working 15 months after palliative pneumonectomy. Growth remains on the wall of the atrium.

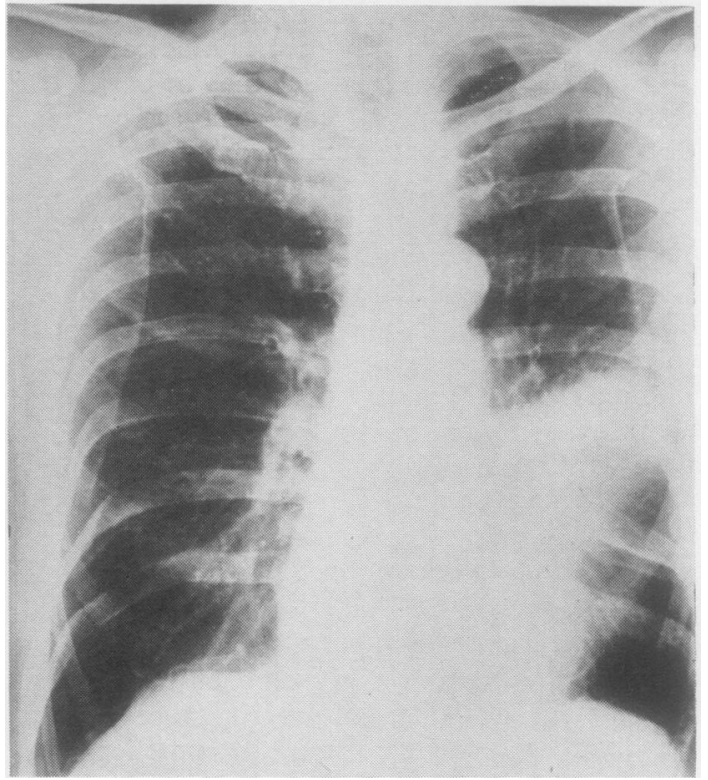

FIG. 5.-Case H. H. (Table II). Pre-operative radiograph. Patient working 19 months after palliative pneumonectomy. Growth remains on the wall of the atrium.

sidered worth while provided the patient lived at least eight months and returned to work. Survival alone in a state of ill health for an eightmonth period did not qualify a patient as a worthwhile result. The period of eight months was

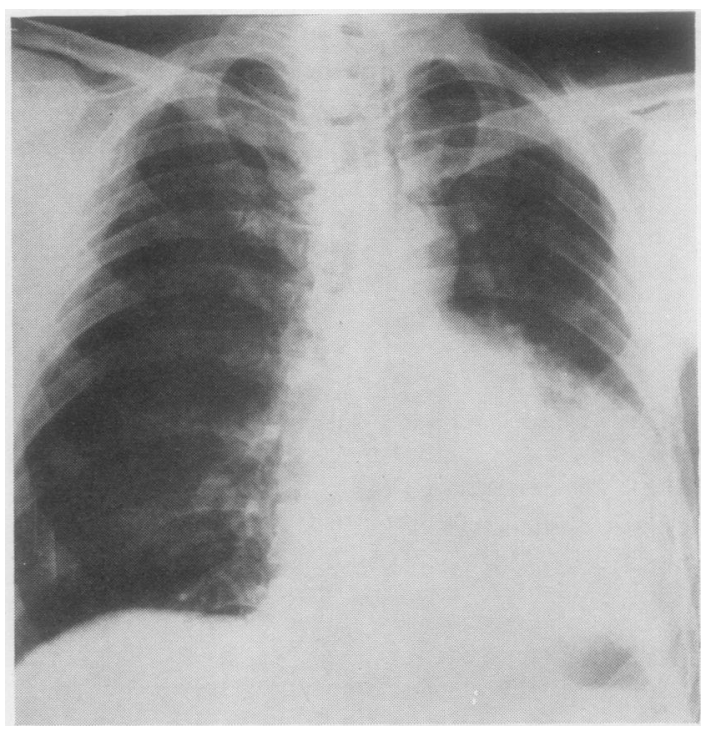

FIG. 7.-Case W, H. (Table II). Pre-operative radiograph. Smal left-sided empyema. Patient working 13 months after palliative pneumonectomy. Growth remains on stump of left pulmonary artery. 
TABLE II

RESULTS OF INTRAPERICARDIAL PALLIATIVE PNEUMONECTOMY IN SURVIVORS LIVING EIGHT MONTHS OR MORE AND RETURNING TO WORK

\begin{tabular}{|c|c|c|c|c|c|c|c|}
\hline Case & Age & Site & $\begin{array}{l}\text { Cell } \\
\text { Type }\end{array}$ & $\begin{array}{c}\text { Site } \\
\text { of Residual } \\
\text { Carcinoma }\end{array}$ & $\begin{array}{l}\text { Alive } \\
\text { or } \\
\text { Dead }\end{array}$ & $\begin{array}{l}\text { Time Since } \\
\text { Operation } \\
\text { (Months) }\end{array}$ & $\begin{array}{c}\text { Clinical } \\
\text { Evidence of Extension } \\
\text { of Growth }\end{array}$ \\
\hline 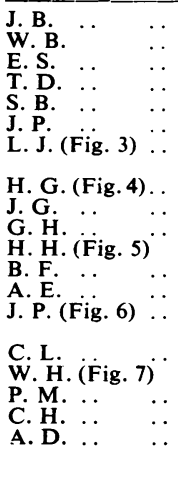 & $\begin{array}{l}55 \\
47 \\
50 \\
66 \\
60 \\
55 \\
48\end{array}$ & $\begin{array}{l}\text { R.U.L. } \\
\text { R.L.L.' } \\
\text { R.U.L. } \\
\text { L."main } \\
\text { L.U.'̈. } \\
\text { L. main } \\
\text { R.'.' } \\
\text { L.L.'. } \\
\text { L.'main } \\
\text { L.L.L. } \\
\text { L.U.L. } \\
\text { R.M.L. } \\
\text { L.L.L. } \\
\text { R.L.L. } \\
\text { L.'̈.L. }\end{array}$ & $\begin{array}{l}\text { Squamous } \\
\text { Oat-cell } \\
\text { Squamous } \\
,, \\
\text { Oat-cell } \\
\text { Adenocar- } \\
\text { cinoma } \\
\text { Squamous } \\
,, \\
\text { Oat-cell } \\
\text { Squamous } \\
\text { Oat-cell } \\
\text { Squamous } \\
\text { Oat-cell } \\
\text {," } \\
\text { Adenocar- } \\
\text { cinoma }\end{array}$ & $\begin{array}{l}\text { In bronchus } \\
\text { On atrium } \\
\text { In 2nd right rib } \\
\text { Mediastinal glands } \\
\text { On base of aorta } \\
\text { O’n pülmonary artery } \\
\text { Mediastinal glands } \\
\text { Supra azygos glands } \\
\text { On atrium } \\
\text { Mediastinal glands } \\
\text { On atrium ", } \\
\text {,", ,", pulmonary artery } \\
\text { Mediastinal glands } \\
\text { On atrium , } \\
\text {, , }\end{array}$ & $\begin{array}{l}\text { Working } \\
\text { Dead } \\
\text {," } \\
\text { Working } \\
\text { Wö, } \\
\text { Dead } \\
\text { Working } \\
\text { Dead } \\
\text { Working } \\
\quad,, \\
\text {," } \\
\text { Dead } \\
\text { Working }\end{array}$ & $\begin{array}{l}58 \\
15 \\
14 \\
17 \\
17 \\
14 \\
26\end{array}$ & $\begin{array}{l}\text { None } \\
\text { Glands in neck } \\
\text { Dorsal spine metastasis } \\
\text { S.V.C. obstruction } \\
\text { Liver metastasis } \\
\text { Glands in neck } \\
\text { None } \\
\text { Small, single neck gland } \\
\text { Rib metastases + neck glands } \\
\text { Brain metastasis } \\
\text { None } \\
\text { Brain metastasis } \\
\text { Metastasis in scar removed } \\
\quad 6 \text { months post-operatively } \\
\text { None } \\
\text { " } \\
\text { Brain metastasis } \\
\text { None }\end{array}$ \\
\hline
\end{tabular}

chosen for no specific reason, but merely as a means of assessing results. On this rather severe test of the value of the operation exactly half of the survivors of the operation, that is to say 19 patients, survived eight months or more and returned to work. The details of the survivors are given in Table II. The results may be summarized in round figures by saying that of the 48 palliative operations, the operative mortality was $10(20 \%)$ and that the operation in half the survivors, that is 19 out of 38, was considered worth while. We should expect no significant change in these results, if the series were repeated, or if the total number of cases were very much larger, provided that the indications for operation remained constant and resection was carried out in a similar percentage of cases. The results in the later period were very much worse than those of the first half of the series, and this may be explained by the inclusion, not deliberately, of a number of cases in the later period which would have been excluded earlier. This tendency to increase the scope of operation beyond the accepted indications seems in all respects undesirable.

\section{Discussion}

If the necessity for operation is accepted, any discussion on the results to be expected from deep $x$-ray therapy for the whole series would be valueless, and obviously it is impossible to divide the series into curative and palliative groups before operation, and a discussion therefore on the results of offering only the palliative group the advantages of this treatment alone is equally valueless. The mor- tality rate of $20 \%$ for palliative resection is high. This is, however, not the mortality rate of an operation deliberately undertaken for incurable cancer but the results to be expected from resection when the local extent of the growth is manifest at operation. When compared with results of closure of the chest without resection of the growth this figure seems less excessive. Ochsner and others (1954) give a figure for hospital mortality of $18 \%$ for 298 non-resectable growths, and Taylor (1954), in an analysis of 330 cancers found at operation to be inoperable, reported that $31 \%$ of these patients died in the first three months after exploration. Although these figures collected from the earliest days of resection to the present day may not reflect the current mortality rate, they do indicate that exploration and closure is an operation which carries a considerable early mortality without benefit of any sort to the patient other than confirmation that no surgical treatment is possible. Obviously a number of factors which need not be discussed contribute to the operative mortality of exploratory thoracotomy. The worthwhile result in half of the survivors of palliative resection has been mentioned. Although the remaining survivors all died with demonstrable metastases at periods up to one year after resection it is worth noting that all, except two who developed bone secondaries within two weeks of operation, were in hospital for only 16 days after operation and none developed symptoms, such as gross respiratory insufficiency or the sequelae of infection in the pneumonectomy space, directly referable to the operation. Haemoptysis and 
excessive sputum have been relieved, but no conclusion can be reached on the place of palliative surgery in relieving chest pain. Pain is conceivably aggravated by operation in some cases, and this unfortunately is the symptom for which a number of patients stand in need of palliation in the later stages of the disease. A closer analysis of the causes of pain, both before and after resection, in a much larger number of cases than reported here is necessary to be convincing on this point. The failure to relieve or forestall the onset of pain has been the most disappointing feature of palliative resection. Bignall (1955), investigating the manner of death in cases of lung carcinoma which had been treated by resection and had died, did not find any patient out of 25 cases with intense pain as a terminal symptom. The problem is a complex one and further discussion would be out of place.

In addition to the length of survival and the general state of the patient during that period, we have tried to determine the effect of palliative resection on the length of the terminal illness as another means of assessing its value. The natural advance of the disease is effectually altered in the terminal stages by the administration of some form of narcotic for the relief of symptoms.

A good palliative procedure in the management of lung cancer can be regarded as one which lengthens the interval of time between diagnosis and the necessity for narcotics and reduces the period during which these drugs are necessary. The latter period when the patient is more or less incapable of caring for himself corresponds to the terminal illness. This tortuous definition takes into account the patient with an advanced growth symptomless at the time of operation whose future must be considered. The effect of palliative resection on the length of the terminal illness has been judged by the following simple method. The survivors of palliative resection were observed at

TABLE III

LENGTH OF TERMINAL ILLNESS AFTER PALLIATIVE RESECTION

Number of survivors

Died during period of follow-up

Attended hospital within one month of death

Prolonged terminal illness (over one month)

monthly intervals. Any patient in reasonable comfort at the time of his last out-patient visit who died during the following month was considered to have had a terminal illness of a month or less. An attempt to measure the length in more definite terms placed too much dependence on such factors as the patient's over-eagerness to co-operate. It was nevertheless possible to ascertain that in a fair proportion the patient's final illness was to be measured in days. The explanation of the frequency of this rapid termination appears to be twofold. That resection, by removing a septic focus, maintains the general condition until extension of the growth kills, and that the patient with only one lung is more prone to a rapidly fatal pulmonary infection especially if there is bronchial obstruction by malignant glands. As to the cause of death, the incidence of cerebral metastases, as described by Bignall (1955), was high. A manner of death which was noted in two patients seems worth recording because of the possibility of recognizing and treating the condition in the future. Both these patients were admitted to hospital some time after palliative resection in a comatose state. They had complained of weakness for some weeks preceding their admission. A diagnosis of cerebral metastases was made. At necropsy the findings were similar in each case. The brain was normal and the only demonstrable cause of death was replacement of all the adrenal gland tissue by secondary carcinoma.

The differences in results between the various methods of treating lung carcinoma which has advanced to the stage of involvement of the mediastinal structures are not great. As long as thoracotomy remains the only certain method of deciding on operability and resection the only known cure, it seems reasonable to proceed to palliative resection in every case in which this operation is possible. On the evidence of this series there seems no reason to abandon this practice.

\section{SUMMARY}

The results of palliative resection for lung

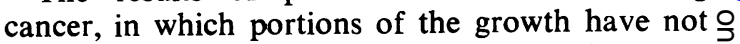
been removed, are reported and discussed.

Dr. D. R. Rigg and Dr. J. C. A. Raison have been $\bar{N}$ associated with the treatment of these patients, and $I \Omega$ am grateful to them for their co-operation. Mr. L. N Hine photographed the specimens and Mr. G. B. Hol- స్心 land, A.I.B.P., reproduced the radiographs.

Aylwin, J. A. (1951) Thorax, 6,250.

Bignall, J. R. (1955). Lancet, 2, 210.

Brock, Russell, and Whytehead, L. L. (1955). Brit. J. Surg., 43, 8. T Ochsner, A., Ray, C. J., and Acree, P. W. (1954). J. Louisiana St. med. Soc., 106, 263.

Sellors, T. Holmes (1950). In Techniques in British Surgery, ed. (D) Maingot, R., p. 188. Saunders, London.

(1952). J. int. Chir., 12, 1.

Taylor, A. B. (1954). United Birmingham Hospitals: Annual Cancer Report, vol. 2, p. 36.

Thompson, V. C. (1952). In Diseases of the Chest, ed. Marshall, G and Perry, K. M. A., vol. 2, p. 328. Butterworth, London. 